\title{
Size-logging interactions and population dynamics in tropical understorey birds
}

\author{
Umesh Srinivasan ${ }^{1,2, *}$ and Suhel Quader ${ }^{1,3}$ \\ ${ }^{1}$ National Centre for Biological Sciences, GKVK Campus, Bengaluru 560 065, India \\ ${ }^{2}$ Programme in Science, Technology and Environmental Policy, Woodrow Wilson School of Public and International Affairs, \\ Princeton University, Princeton NJ 08540, USA \\ ${ }^{3}$ Nature Conservation Foundation, Mysuru 570 002, India
}

Demographic vital rates (e.g., fecundity and survival) determine population size and viability. However, how anthropogenic habitat change differentially influences these dynamic population processes for species with different traits remains unknown. Crucially, this limits a mechanistic understanding of species- and community-level patterns in response to intensity of habitat change, and therefore, impedes robust prediction of future species responses. We investigated how size (across 26 forest birds, spanning almost an order of magnitude in body mass) and habitat modification (logging intensity, from intact forest to a $\mathbf{2 . 5}$-fold reduction in tree density) might interact to influence survival, reproduction and dispersal. Data were collected over five sessions under the robust design in a capture-mark-recapture framework and analysed using reverse time capture-recapture models. We found that smaller species were more fecund with increased logging intensity, and dispersed from more heavily logged to more intact forest. With increasing size, species reproduced better in progressively more intact forest, and dispersed from intact forest into more logged forest. These results indicate important trait-linked differences in the relative significance of various demographic processes in influencing species responses to varying intensities of habitat change. Separating the mechanistic processes underlying observed patterns is crucial to understanding and predicting anthropogenic impacts on biodiversity.

Keywords: Apparent survival, eastern Himalaya, fecundity, natal dispersal, reverse time mark-recapture, understorey insectivores.

HUMANS continue to imperil tropical biodiversity at an alarming rate, through forest fragmentation, hunting and $\log \operatorname{sing}^{1-4}$. Selective logging is currently the dominant regime of forest modification across the tropics ${ }^{5}-\mathrm{a}$ fifth of all tropical forests was selectively logged between 2000 and 2005, and vast parts of the tropics continue to be logged ${ }^{5}$. Selective logging results in a decline in the number of species of diverse taxa (including invertebrates, amphibians, forest birds and mammals) ${ }^{6}$, as well

*For correspondence. (e-mail: umesh.srinivasan@gmail.com) as reduced abundances of a major proportion of forestdependent fauna ${ }^{7}$.

Inferences on the differential impacts of environmental change (including logging) have so far been drawn from species-specific or, at the other extreme, community-level patterns (e.g., the presence and/or abundances of species $)^{7}$. Although such studies are useful from an applied perspective, they fail to uncover the interplay of demographic mechanisms or vital rates (such as reproduction, survival and dispersal) that lead to emergent patterns in species presence or abundance. Several studies have indeed examined the impact of environmental modification on the population dynamics of single species ${ }^{8-10}$. However, inferences from single-species studies, by definition, cannot be generalized.

Dynamics population processes such as fecundity and survival are intimately linked to species traits, especially body mass ${ }^{11}$. Further, species traits are correlated to the patterns of species responses to anthropogenic habitat change - for instance, larger species tend to become rarer with logging ${ }^{7,12}$. Despite these patterns, the lack of mechanistic insights on the impact of anthropogenic habitat change on different species has limited our understanding of species responses to environmental modification. Examining the mechanisms underlying emergent species and community patterns requires an understanding of how survival, reproduction and dispersal are affected by the interaction between species traits and the intensity of habitat modification. This is essential because these interactions ultimately determine population viability for different species in different habitats.

For example, equal abundances in logged and intact forest, and an annual population growth rate of one (no change in population size over time) in logged forest can arise from various combinations in the magnitudes of survival, reproduction and immigration. These include: (a) depressed reproduction and high mortality coupled with massive immigration from viable populations in intact forest, indicating a non-viable population in the absence of sources, and (b) high (or low) reproduction coupled with high (or low) mortality but no immigration, indicating a viable population. In these two cases, inferences about the suitability of logged forest for the populations of this species will be vastly different, and simply 
Table 1. Species included in the mark-recapture analyses and their mean body masses

\begin{tabular}{|c|c|c|c|}
\hline Family & Scientific name & English name & Body mass $(\mathrm{g})$ \\
\hline Cettiidae & Abroscopus schisticeps & Black-faced Warbler & 4.7 \\
\hline Cettiidae & Cettia castaneocoronata & Chestnut-headed Tesia & 9 \\
\hline Cettiidae & Tesia cyaniventer & Grey-bellied Tesia & 9.7 \\
\hline Leiothrichidae & Actinodura egertoni & Rusty-fronted Barwing & 36 \\
\hline Muscicapidae & Ficedula hyperythra & Snowy-browed Flycatcher & 8.2 \\
\hline Muscicapidae & Cinclidium leucurum & White-tailed Robin & 31 \\
\hline Muscicapidae & Niltava grandis & Large Niltava & 30.3 \\
\hline Muscicapidae & Niltava sundara & Rufous-bellied Niltava & 21.1 \\
\hline Nectariniidae & Aethopyga nipalensis & Green-tailed Sunbird & 6.9 \\
\hline Pellorneidae & Pseudominla castaneceps & Rufous-winged Fulvetta & 12.5 \\
\hline Pellorneidae & Pseudominla cinerea & Yellow-throated Fulvetta & 11 \\
\hline Phylloscopidae & Phylloscopus reguloides & Blyth's Leaf Warbler & 7.8 \\
\hline Phylloscopidae & Seicercus affinis & White-spectacled Warbler & 7 \\
\hline Phylloscopidae & Seicercus castaneceps & Chestnut-crowned Warbler & 5.3 \\
\hline Phylloscopidae & Seicercus poliogenys & Grey-cheeked Warbler & 6.3 \\
\hline Phylloscopidae & Seicercus whistleri & Whistler's Warbler & 7.3 \\
\hline Rhipiduridae & Rhipidura albicollis & White-throated Fantail & 12.9 \\
\hline Stenostiridae & Culicicapa ceylonensis & Grey-headed Flycatcher & 7.7 \\
\hline Stenostiridae & Chelidorhynx hypoxantha & Yellow-bellied Fantail & 5.5 \\
\hline Sylviidae & Lioparus chrysotis & Golden-breasted Fulvetta & 5.5 \\
\hline Timaliidae & Pomatorhinus ruficollis & Streak-breasted Scimitar Babbler & 30.2 \\
\hline Timaliidae & Spelaeornis caudatus & Rufous-throated Wren Babbler & 11 \\
\hline Timaliidae & Stachyridopsis chrysaea & Golden Babbler & 9 \\
\hline Timaliidae & Stachyridopsis ruficeps & Rufous-capped Babbler & 10.3 \\
\hline Timaliidae & Pomatorhinus superciliaris & Slender-billed Scimitar Babbler & 29 \\
\hline Timaliidae & Yuhina flavicollis & Whiskered Yuhina & 17.5 \\
\hline
\end{tabular}

examining abundance (or even population growth rate) is likely to mislead. Therefore, studying interactions between habitat change intensity and species traits, and how these might relate to various demographic vital rates is crucial for understanding of both patterns, as well as to building a robust predictive framework for future anthropogenic species responses.

We examine how the survival, fecundity and dispersal of 26 differently-sized species (Table 1) of tropical understorey insectivorous birds respond to a gradient of selective logging. We predict that (a) for small species, fecundity is positively related to logging intensity, and natal dispersal is directed from more logged to more intact forest $^{13}$, (b) at some intermediate 'threshold' body size, fecundity and natal dispersal should be unrelated to logging intensity, and (c) species larger than this 'threshold' should show demographic patterns opposite to small species; specifically, fecundity negatively related to increased logging intensity, and natal dispersal from more intact to more logged forest.

\section{Methods}

\section{Study area}

We sampled seven polygonal plots (size range: 2.5$3.8 \mathrm{ha}$ ) representing a gradient in intensity of past logging (from primary forest to intensively logged habitat) in montane wet temperate forest ${ }^{14}$ in the Eaglenest Wildlife Sanctuary, Arunachal Pradesh, India, in the Eastern Himalaya Global Biodiversity Hotspot. Plots were centred around $2000 \mathrm{~m}$ amsl, where the diversity of understorey insectivores peaks in the Eastern Himalaya ${ }^{15}$. A map, and further details of the study site and sampling plots were published earlier ${ }^{13,16}$.

\section{Field sampling}

Within each sampling plot, we used 24-28 point-centred quarters to estimate the density of trees greater than a $10 \mathrm{~cm}$ diameter at breast height ${ }^{17}$. We used tree density as an inverse proxy for logging intensity because tree density correlated well with semi-quantitative estimates of timber extraction levels ${ }^{16}$. Thus, plots that faced greater logging had lower tree densities and vice versa. We sampled the understorey bird community in each of the seven sampling plots using mist-netting $(12 \mathrm{~m}$, four shelf, $16 \mathrm{~mm}$ mesh size) and bird ringing. In each plot, 24-28 nets (185 nets totally across all plots) were placed systematically ( $\sim 40 \mathrm{~m}$ between neighbouring nets), and operated for three consecutive days per plot from $0500 \mathrm{~h}$ to $1200 \mathrm{~h}$. We sampled all plots $(7$ plots $\times 3$ days per plot $=21$ days total per session) in the breeding season (April-May) in 2011, 2012, and 2013, and in the postbreeding season (September-October) in 2012 (2 days per plot) and 2013 (schematic $\left.{ }^{16}\right)$. All birds captured were 
marked with numbered aluminum rings, weighed and released.

We chose to sample bi-annually because the interval between the breeding and post-breeding season would reflect breeding efficiency with individuals added predominantly from reproduction. In contrast, individuals added to plots between the post-breeding to the next breeding interval would be solely from natal dispersal (immigration), because all breeding in the mid-elevation Eastern Himalayas ends by the end of June ${ }^{13,15,16}$. We are mindful of the possibility that individuals added during the breeding to post-breeding interval might also be dispersers. However, such individuals are likely to be few at best, given that tropical passerines show extended parental care, with the young remaining on natal territories for long periods, often even until just before the start of the following breeding season ${ }^{18,19}$.

\section{Study species}

For analyses, we chose only species that were captured on at least 30 occasions across the five sampling sessions. A total of 26 species (about half the species in the understorey insectivorous bird community) were included in the analysis. These species ranged in body size from $4.7 \mathrm{~g}$ (Abroscopus schisticeps [black-faced warbler]) to $36.0 \mathrm{~g}$ (Actinodura egertoni [rusty-fronted Barwing]; Table 1).

\section{Analytical methods}

We used reverse-time mark recapture modelling ${ }^{20}$ in the R package RMark $^{21,22}$ to estimate apparent survival $(\Phi)$ and per-capita recruitment $(f)$, while simultaneously accounting for imperfect detection (i.e. capture probability $<1)$. In forward time, the transition probability estimated by mark-recapture analyses is apparent survival, or the probability of surviving and remaining in the population between two time steps. Reverse-time mark-recapture takes advantage of the fact that the transition probability estimated on reversing the capture histories is the probability of entering the population at the subsequent time step $^{20}$, and therefore can be used to estimate recruitment.

We estimated apparent survival and recruitment separately for the two biologically relevant time intervals breeding to post-breeding, and post-breeding to breeding. Because we had five sampling occasions, we had four time intervals, two each for breeding to post-breeding, and post-breeding to breeding. We constrained the markrecapture models such that they estimated one value for apparent survival and per-capita recruitment for each of the two biologically different time intervals ${ }^{13}$. To explore the relationship between the intensity of selective logging and species traits, we used tree density and the average body mass of each species as individual covariates - each individual's capture history was linked to (a) the tree density of the plot of capture, and (b) the mean body mass of all captured individuals of that species.

We selected certain formulations of model parameters based on our expectations arising from the biology of our study species. Capture probability was formulated to be either (a) dependent on species identity, or (b) dependent on body mass. Capture probability might vary with species identity because of differences in species behaviour. At the same time, one might expect that capture probability depends on the home ranges of species, and perhaps body size, because larger species are likely to have larger home ranges (and therefore lower capture probability). The formulations for apparent survival and per-capita recruitment were as follows.

Apparent survival: $\Phi($ interval + mass + tree + interval $\times$ mass + interval $\times$ tree + tree $\times$ mass + interval $\times$ tree $\times$ mass), where 'interval' represents the two biologically interesting time intervals noted previously; 'tree' represents tree density as an individual covariate, and 'mass' the log of body mass in grams, as an individual covariate.

From our prior work on small understorey insectivores $^{13}$, apparent survival during the breeding to postbreeding interval is not strongly related to tree density. We did not strongly expect apparent survival during the post-breeding to the breeding interval to change qualitatively with body mass. This is because apparent survival is a composite of both true survival and (lack of) movement, the relative strengths of which we expected to differ for differently-sized species. However, we still tested whether the relationship between survival and tree density is related to body mass.

Per-capita recruitment: We expected per-capita recruitment during the breeding to post-breeding time interval to be monotonically related to tree density, but negatively for small species ${ }^{13}$, invariant for intermediatesized species, and positively for large species. We therefore investigated for interactions between body mass, tree density and time interval using the following formulation (the three main effects and all possible interactions) for recruitment: $f$ (interval + mass + tree + interval $\times$ mass + interval $\times$ tree + tree $\times$ mass + interval $\times$ tree $\times$ mass $)$. In addition, however, in an exploratory exercise, we also examined the possibility that intermediate-sized species might show a unimodal relationship between tree density and fecundity, with highest fecundity at intermediate tree densities. We therefore also investigated a formulation with a quadratic term to allow for a unimodal relationship of per-capita recruitment on tree density, as follows: $f\left(\right.$ interval + mass + tree + tree $^{2}+$ interval $\times$ mass + interval $\times$ tree + interval $\times$ tree $^{2}+$ tree $\times$ mass + mass $\times$ tree $^{2}+$ interval $\times$ mass $\times$ tree + interval $\times$ mass $\times$ tree $^{2}$ ).

We used the same two-model formulation of per-capita recruitment to investigate addition of individuals from the 


\section{RESEARCH ARTICLES}

post-breeding to breeding time interval (i.e., recruitment from immigration) with tree density. In this time interval, we expected the relationship to be positive for small species, invariant for intermediately-sized species, and negative for large species; in addition, we also explored a unimodal relationship (with the quadratic term in the second formulation) between tree density and recruitment. Given all combinations of model formulations for capture probability (2), apparent survival (1) and recruitment (2), we therefore tested four candidate models $(2 \times 1 \times 2)$.

For model selection, we used small-sample sizecorrected Akaike Information Criterion (AICc), which trades off model fit with model complexity to select the best simplest model ${ }^{23}$. For visualization, standard errors around predicted trends were estimated using the delta method, a first-order Taylor series approximation that uses information from the parameter estimates and the variance-covariance matrix of the estimated parameters ${ }^{24,25}$.

\section{Results}

In all, we analysed 3,244 captures of 2,597 individuals across the 26 selected species (Table 1). The model with (a)
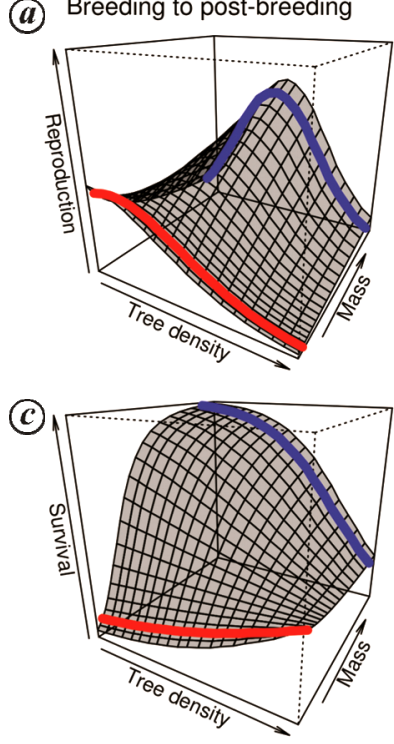
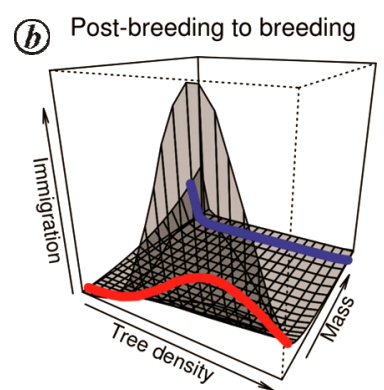

(d)

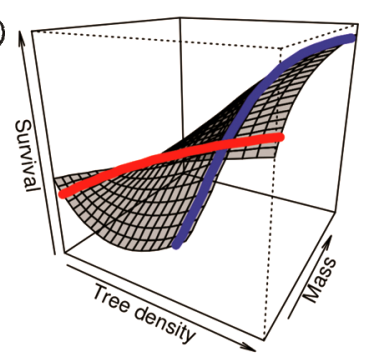

Figure 1. Results from the mark-recapture model showing the relationship between vital rates ( $z$-axis) and the interaction between tree density ( $x$-axis) and body mass ( $y$-axis). Note that higher tree density means lower logging intensity. $\boldsymbol{a}$, For smaller species (red curve), breeding declines monotonically with increasing tree density; for larger species (blue curve), breeding peaks at intermediate tree densities. $\boldsymbol{b}$, Smaller species immigrate into habitats with higher tree densities; larger species show the opposite pattern. $c$, Apparent survival is related to tree density monotonically, but in opposite directions for small (increasing) and large (declining) species during the breeding to postbreeding interval. $\boldsymbol{d}$, Both small and large species show lower apparent survival in logged forest in the post-breeding to breeding interval. The red and blue curves in each of the panels are plotted in two dimensions in Figure 2. species-varying capture probability and a quadratic formulation for recruitment had clear support over all other models $(\triangle \mathrm{AICc}$ for the other three competing models $=$ $18.67,207.60,204.00)$, despite estimating the maximum number of parameters of all models (46 parameters, compared to 42,18 and 22 estimated by the three other models). We report results from the most parsimonious model below. Note that although we examined demographic responses along a body mass continuum (Figure 1), for ease of understanding and inference, we report and discuss the demography of 'smaller' ( $\sim 6 \mathrm{~g})$ and 'larger' $(\sim 32 \mathrm{~g})$ species (Figure 2$)$. These particular masses were selected to represent small and large species because they are close to the masses of the smallest and largest species ( $4.7 \mathrm{~g}$ and $36.0 \mathrm{~g}$, respectively) included in our analyses (Table 1). For illustration, we also discuss 'intermediate'sized species $(\sim 18 \mathrm{~g})$.

Smaller species showed a negative relationship between tree density and fecundity, with highest fecundity in

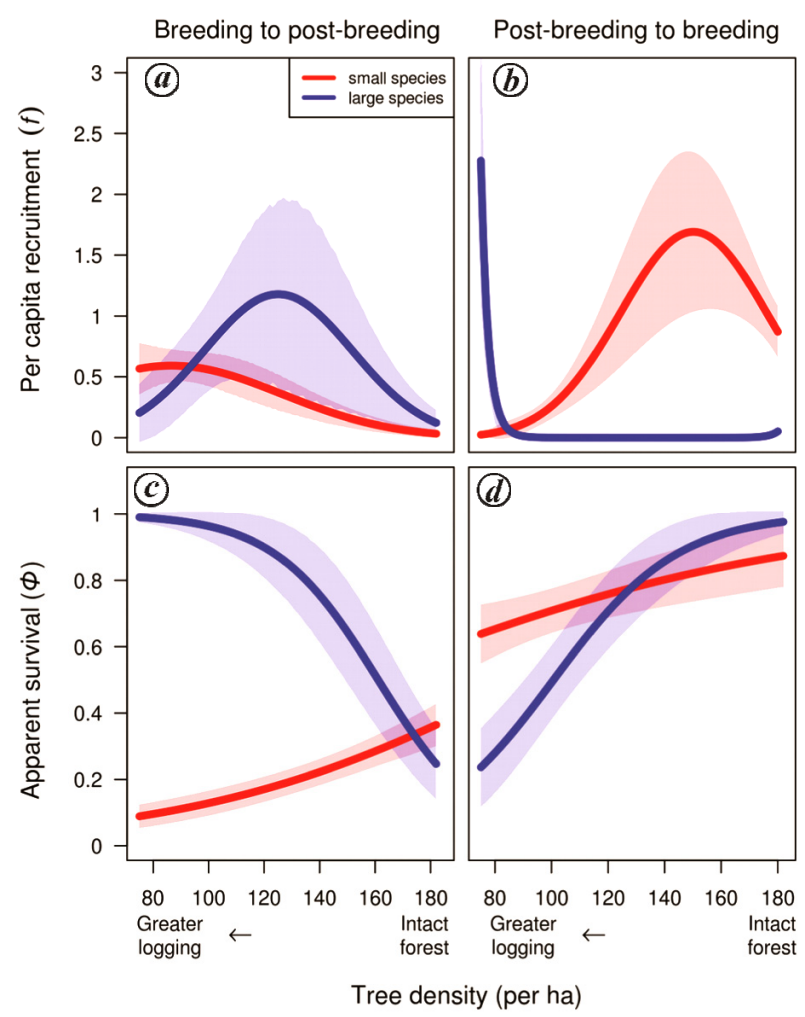

Figure 2. Modelled relationship between vital rates and tree density for smaller ( $\sim 6 \mathrm{~g}$; red) and larger $(\sim 32 \mathrm{~g}$; blue) species with tree density. Polygons represent one standard error around the modelled estimates. Small species breed better at low tree densities, and reproduction of larger species peaks at intermediate tree densities $(\boldsymbol{a})$. Smaller species appear to disperse from more logged to more intact forest, whereas the opposite appears true for larger species $(\boldsymbol{b})$. Opposite patterns in apparent survival with tree density for small and large species during the breeding to post-breeding interval $(c)$ might reflect costs of reproduction arising from greater breeding in logged forest for small species and in intact forest for large species. Lower apparent survival in logged forest in the post-breeding to breeding interval $(\boldsymbol{d})$ might reflect natal dispersal for small species and increased mortality for large species. 
forest patches with the least tree density (Figures $1 a$ and $2 a$ ), and dispersal into forest patches with higher tree densities (Figures $1 b$ and $2 b$ ). We expected that for larger species, fecundity and immigration would be independent of tree density. However, we found that as body size increased, both fecundity and immigration showed a unimodal relationship with tree density - peak fecundity occurred at intermediate tree densities, with progressively larger species showing this peak at progressively higher tree densities (Figures $1 a$ and $2 a$ ). In keeping with our expectation of immigration for larger species being from more intact to more logged forest, larger species showed immigration into low tree-density plots (Figures $1 a$ and $2 a)$.

Apparent survival during the breeding to post-breeding interval increased with tree density for small species (Figures $1 c$ and $2 c$ ). This pattern was reversed for larger species, that showed declining survival with increased tree density (Figures $1 c$ and $2 c$ ). During the postbreeding to breeding interval, apparent survival increased with tree density for both small and large species. However, this increase was much stronger for large species compared to small species (Figures $1 d$ and $2 d$ ).

\section{Discussion}

We report patterns in fecundity, dispersal and apparent survival in relation to logging intensity for 26 tropical understorey insectivorous birds that span almost an order of magnitude in body mass (Table 1). We found that smaller species were fecund in more logged forest, and dispersed into more intact forest, which is consistent with our predictions and prior work ${ }^{13}$ (Figures $1 a, b ; 2 a$ and $b)$. Contrary to our expectation, however, for none of the larger species was fecundity or immigration unrelated to logging intensity, and none showed monotonically increasing fecundity with increasing tree density or clear evidence of movement from more intact to more logged forest. Instead, larger species showed a unimodal relationship between fecundity and logging intensity, with peak fecundity in progressively more intact forest with increasing body mass (Figures $1 a$ and $2 a$ ). Also contrary to expectation, larger species showed near-zero dispersal across the gradient of logging intensity (Figures $1 b$ and $2 b)$.

For small species, higher fecundity in logged forest (Figures $1 a$ and $2 a$ ), lower survival in more heavily logged forest during the natal dispersal period (Figures $1 d$ and $2 d$ ), and greater immigration into more intact forest (Figures $1 b$ and $2 b$ ) suggests that selective logging is demographically beneficial to small species. This might be because of the loss of larger species in logged forest $^{16}$, leading to density compensation and enhanced reproduction by smaller species ${ }^{26}$. For larger species, fecundity increased with greater forest intactness initially
(Figures $1 a$ and $2 a$ ), but declined in the most intact forest patches - a pattern that is unexpected. Intermediate apparent survival during the natal dispersal period (Figures $1 c$ and $2 c$ ) in high fecundity patches, and increased immigration into more logged patches (Figures $1 b$ and $2 b$ ) indicates that high reproductive output at intermediate logging intensities is followed by natal dispersal from these patches to more logged patches in larger species - a pattern that is opposite to that of smaller species.

For both small and large species, apparent survival during the natal dispersal period is high in intact forest (Figures $1 d$ and $2 d$ ), indicating that individuals fledged in intact forest survive well and stay on natal grounds regardless of body size. Poor apparent survival for small species during this period (Figures $1 d$ and $2 d$ ) can be explained by increased dispersal out of logged habitat (when examined in the light of other demographic patterns, as noted above). However, reduced apparent survival of large species in logged forest (Figures $1 d$ and $2 d$ ) is unlikely to be from dispersal, given the almost uniformly low immigration of larger species (Figures $1 b$ and $2 b$ ). We therefore believe it likely that individuals of larger species in more heavily logged forest disappear from these habitats because of mortality, rather than because of movement out of these patches. This indicates important differences in the relative contributions of mortality and dispersal in the life-histories of small versus large species, strongly hinting at very different demographic mechanisms underlying changes in species abundances in response to anthropogenic habitat change. The template of different allocation of resources to survival, reproduction and movement for large and small species is likely to be modified to varying degrees by environmental change (see ref. (10) for a single-species study).

Apparent survival following the breeding season shows opposite patterns for small and large species (Figures $1 c$ and $2 c$ ) - small species survive better in more intact forest, whereas larger species have greater survival in more logged forest. These patterns require further investigation. We think it unlikely that dispersal out of the sampling plots might be an important determinant of these patterns because understorey insectivores are likely to remain on territories with their young until the subsequent breeding season ${ }^{18,19}$. We think it likely, therefore, that mortality underlies these patterns. One tentative hypothesis is that the cost of reproduction gives rise to these relationships ${ }^{27}$. Smaller species might face increased mortality in more heavily logged patches during this time interval because higher investment in reproduction in logged forest might result in decreased survival. If indeed, as our results partly suggest, larger species are more fecund in more intact forest, then the opposite pattern for these species might be explained by greater costs of reproduction for large species in intact forest. However, we note that this hypothesis is entirely speculative, and needs to be tested by directly following individual fate 


\section{RESEARCH ARTICLES}

and reproductive effort ${ }^{28}$ along the gradient of logging intensity.

A surprising finding from our results is that larger species show negligible movement and dispersal, unlike patterns reported previously, where larger species are more likely to disperse farther ${ }^{29}$. Prior empirical and experimental evidence strongly suggests that, as a guild, understorey insectivores tend to be dispersal-limited ${ }^{30}$, especially in human-modified forests ${ }^{31,32}$. Anthropogenic dispersal limitation (from fragmentation, for instance) might disproportionately affect larger species, a potential mechanism further enhancing their vulnerability to anthropogenic habitat change. This hypothesis could be tested using data from radio telemetry, or from translocation experiments examining a range of species' body sizes ${ }^{33}$.

We must caution that in our study site (and globally), there are much larger understorey insectivores (e.g., laughing thrushes - genus Garrulax), to which the models we report here cannot be directly applied using the model-estimated parameters. In our study site, and in general, larger bird species tend to be rare in disturbed habitats ${ }^{16,34}$, and from our own dataset (with sparse data for very large species, which we exclude here), we were unable to include robust data to model the interaction between body mass and logging for these rare species. However, intrinsically rare species are often the most vulnerable to anthropogenic change $\mathrm{e}^{35}$. Based on the patterns we present, we predict that peak reproduction with increasing body size will occur at even higher tree densities, until for the largest species, highest reproduction occurs in completely intact forest. Along with long-term demographic data ${ }^{36}$, radio-tagging of nestlings, and telemetry across a logging intensity gradient would provide useful sources of information on natal dispersal and fate of individuals of large species.

We conclude that smaller species are likely to have viable populations even in intensively logged forest, whereas populations of the largest species are likely to be unviable in logged habitats without the rescue effect of immigration from source populations in intact forest. Mere presence (or even unchanging abundances) of different species in logged or modified habitat, therefore, can arise from vastly different mechanisms, and can have very different demographic consequences in the face of continuing habitat change. To our knowledge, this is the first exploration of how species traits might interact with a gradient of human-induced habitat modification to influence a variety of key demographic vital rates (survival, recruitment and dispersal). Altered demographic vital rates underlie responses of species population sizes and geographical ranges, and therefore community structure and functioning. Understanding the association between key species traits and demography, and how this association interacts with anthropogenic habitat change is crucial for a robust, mechanistic framework to predict how biodiversity responds to accelerating environmental change.
1. Sekercioğlu, C.. H., Ehrlich, P. R., Daily, G. C., Aygen, D. and Sandi, R. F., Disappearance of insectivorous birds from tropical forest fragments. Proc. Natl. Acad. Sci. USA, 2002, 99, 263-267.

2. Lampila, P., Monkonnen, M. and Desrochers, A., Demographic responses by birds to forest fragmentation. Cons. Biol., 2005, 19, $1537-1546$.

3. Laurance, W. F. et al., Averting biodiversity collapse in tropical forest protected areas. Nature, 2002, 489, 290-294.

4. Edwards, D. P., Tobias, J. A., Shiel, D., Meijaard, E. and Laurance, W. F., Maintaining ecosystem function and services in logged tropical forest. Trends Ecol. Evol., 2004, 29, 511-520.

5. Edwards, D. P. and Laurance, W. F., Biodiversity despite selective logging. Science, 2013, 339, 646-647.

6. Burivalova, Z., Sekercioglu, C. H. and Koh, L. P., Thresholds of logging intensity to maintain tropical forest biodiversity. Curr. Biol., 2014, 24, 1893-1898.

7. Burivalova, Z., Lee, T. M., Giam, X., Sekercioglu, C. H., Wilcove, D. S. and Koh, L. P., Avian responses to selective logging shaped by species traits and logging practices. Proc. R. Soc. B, 2015, 282, 20150164

8. Powell, L. A., Lang, J. D., Conroy, M. J. and Krementz, D. G., Effects of forest management on density, survival, and population growth of wood thrushes. J. Wildlife Manage., 2000, 2000, $11-23$.

9. Bayne, E. M. and Hobson, K. A., Apparent survival of male Ovenbirds in fragmented and forested boreal landscapes. Ecology, 2002, 83, 1307-1316.

10. Ozgul, A. et al., Coupled dynamics of body mass and population growth in response to environmental change. Nature, 2010, 466, 482-485.

11. Brawn, J. D., Karr, J. R. and Nichols, J. D., Demography of birds in a neotropical forest: effects of allometry, taxonomy and ecology. Ecology, 1995, 76, 41-51.

12. Velho, N., Ratnam, J., Srinivasan, U. and Sankaran, M., Shifts in community structure of tropical trees and avian frugivores in forests recovering from past logging. Biol. Cons., 2012, 153, 3240 .

13. Srinivasan, U., Hines, J. E. and Quader, S., Demographic superiority with increased logging in tropical understorey insectivorous birds. J. Appl. Ecol., 2015, 52, 1374-1380.

14. Champion, H. G. and Seth, S. K., A Revised Survey of the Forest Types of India, Director of Publications, Government of India, New Delhi, 1968.

15. Rasmussen, P. C. and Anderton, J. C., Birds of South Asia: The Ripley Guide, Smithsonian Institution and Lynx Edicions, Barcelona, 2012.

16. Srinivasan, U., A slippery slope: logging alters mass-abundance scaling in ecological communities. J. Appl. Ecol., 2013, 50, 920 928.

17. Mitchell, K., Quantitative analysis by the point-centred quarter method, 2012; http://people.hws.edu/mitchell/PCQM.pdf

18. Russell, E. M., Yom-Tov, Y. and Geffen, E., Extended parental care and delayed dispersal: northern, tropical and southern passerines compared. Behav. Ecol., 2004, 15, 831-838.

19. Sankamethawee, W., Hardesty, B. D. and Gale, G. A., Sex-bias and timing of natal dispersal in cooperatively breeding puffthroated Bulbuls Aliophoixus pallidus. J. Ornithol., 2010, 151, 779-789.

20. Pradel, R., Utilization of capture-mark-recapture for the study of recruitment and population growth rate. Biometrics, 1996, 52, 703-709.

21. Laake, J. and Rexstad, A., RMark: An alternative approach to building linear models in Mark, 2008; www.phidot.org

22. R Core Team, R: A language and environment for statistical computing. R Foundation for Statistical Computing. Vienna, Austria. ISBN 3-90051, 2013; http://www.r-project.org 


\section{RESEARCH ARTICLES}

23. Burnham, K. P. and Anderson, D. R., Model Selection and Multimodel Inference, Springer Science \& Business Media, 2002.

24. Powell, L. A., Approximating variance of demographic parameters using the delta method: a reference for avian biologists. Condor, 2009, 109, 949-954.

25. Cooch, E. and White, G., Program MARK: A Gentle Introduction, 2006; available in .pdf format for free download at http://www. phidot.org/software/mark/docs/book

26. O'Gorman, E. J. and Emerson, M. C., Body mass-abundance relationships are robust to cascading effects in marine food webs. Oikos, 2001, 120, 520-528.

27. Santos, E. S. A. and Nakagawa, S., The costs of parental care: a meta-analysis of the trade-off between parental effort and survival in birds. J. Evol. Biol., 2012, 9, 1911-1917.

28. Buowhius, S., Choquet, R., Sheldon, B. C. and Verhulst, S., The forms and fitness cost of senescence: age-specific recapture, survival, reproduction, and reproductive value in a wild bird population. Am. Nat., 2012, 179, 15-27.

29. Sutherland, G. D., Harestad, A. S., Price, K. and Lertzman, K. P., Scaling of natal dispersal distances in terrestrial birds and mammals. Cons. Biol., 2000, 4, 16.

30. Moore, R. P., Robinson, W. D., Lovette, I. J. and Robinson, T. R., Experimental evidence for extreme dispersal limitation in tropical forest birds. Ecol. Lett., 2008, 11, 960-968.

31. Belisle, M., Desrochers, A. and Fortin, J.-M., Influence of forest cover on the movements of forest birds: a homing experiment. Ecology, 2001, 82, 1893-1904.

32. Laurance, S. G. W., Stouffer, P. C. and Laurance, W. F., Effects of road clearings on movement patterns of understorey rainforest birds in central Amazonia. Cons. Biol., 2004, 18, 1099-1109.
33. Castellon, T. D. and Sieving, K. E., An experimental test of matrix permeability and corridor use by an endemic understorey bird. Cons. Biol., 2006, 20, 135-145.

34. Sodhi, N. S., Liow, L. H. and Bazzaz, F. A., Avian extinctions from tropical and subtropical forests. Ann. Rev. Ecol. Evol. Syst., 2004, 2004, 323-345.

35. Gaston, K. J., Rarity as double jeopardy. Nature, 1998, 394, 229 230; doi:10.1038/28288.

36. Korfanta, N. M., Newmark, W. D. and Kaufman, M. J., Longterm demographic consequences of habitat fragmentation to a tropical understorey bird community. Ecology, 2012, 93, 25482559.

ACKNOWLEDGEMENTS. We thank the Arunachal Pradesh Forest Department for providing permission to carry out this project, and for their support to this study. R. Athreya supported this project in various ways, and especially in the last field season. We thank S. Rai, G. Rana, D. Subba and B. Tamang for help in the field, and I. Glow and N. Tsering for logistical help. U.S. thanks Z. Burivalova for detailed and helpful comments on the manuscript. U.S. thanks N. Velho for support throughout this work. The International Foundation for Science, Sweden, and the National Centre for Biological Sciences, India, funded this work.

Received 6 March 2018; revised accepted 22 November 2018

doi: $10.18520 /$ cs/v116/i5/795-801 